\title{
A PRÁTICA DISCURSIVA DAS CONTRIBUIÇÕES DA ESCOLA DE GESTORES PARA A GESTÃO ESCOLAR DEMOCRÁTICA
}

Lindalva Gouveia Nascimento

\begin{abstract}
Resumo
Objetiva-se analisar as contribuições do Curso de Especialização em Gestão Escolar do Programa Nacional da Escola de Gestores da Educação Básica. Problematizou-se o estudo devido à formação ser voltada para escolas com baixos índices de desenvolvimento. Foram utilizados os documentos oficiais do programa, e constatou-se que estes contêm uma concepção de formação voltada para elementos teórico-práticos viabilizadores da educação com qualidade social. Verificou-se que a formação tem contribuído para mudanças na prática construída a partir da compreensão do princípio de gestão democrática.
\end{abstract}

Palavras chaves: Gestão escolar, qualidade social da educação, formação continuada de professores, gestores.

\begin{abstract}
It aims to analyze the contributions of the Specialization Course in School Management Program Managers National School of Basic Education. Problematized the study due to be turned to training schools with low levels of development. We used the official documents of the program, and found that they contain a conception of training focused on theoretical and practical elements that enable the social quality education. It was found that training has contributed to changes in practice built on the understanding of the principle of democratic management.
\end{abstract}

Keywords: School management, social quality of education, continuing education of teachersmanagers.

\section{APRESENTAÇÃO}

Este artigo apresenta os resultados da pesquisa desenvolvida durante o Mestrado do Programa de Pós-Graduação em Educação, na Linha de Políticas Educacionais, da Universidade Federal da Paraíba, intitulada A prática discursiva das contribuições da Escola de Gestores para a gestão escolar democrática que foi realizada com o intuito de suscitar no âmbito escolar a discussão em relação à implantação de programas educacionais. A quem serve? E com que propósito são criados?

Do conjunto das políticas públicas para a educação básica propostas e 
coordenadas pelo Ministério da Educação (MEC) e concebidas para serem desenvolvidas a partir do regime de colaboração com estados e municípios, encontra-se o Programa Nacional Escola de Gestores da Educação Básica Pública (PNEGEBP), que conta com a participação de instituições e de entidades representativas do campo educacional que, de algum modo, buscam influenciar os rumos das políticas educacionais em curso, em que pesem estas terem ingredientes político-institucionais que ultrapassam os limites da interferência desses setores (AGUIAR, 2010).

Pretende-se analisar o projeto de maior envergadura do PNEGEBP, que é o curso de Especialização em Gestão Escolar, de forma a tematizar o processo de formulação, avaliação e implementação do projeto do curso como política de formação de gestores escolares, que procura consolidar, nas práticas de gestão escolar, o princípio da gestão democrática da escola e a concepção de educação como direito e de qualidade social.

O curso é realizado em parceria com universidades federais, e a Universidade Federal da Paraíba (UFPB) é parceira na implementação desta política pública ${ }^{1}$ desde 2008 , a qual já tem inúmeros gestores formados no Estado da Paraíba, já sendo possível aferir resultados ou o impacto da implementação dessa ação governamental.

A proposta de formação é voltada a atuação do gestor na perspectiva da gestão democrática e da educação inclusiva, e intenta contribuir para a melhoria do Índice de Desenvolvimento da Educação Básica (BRASIL/MEC/2009).

Outro aspecto que desperta inquietações é que a formação do PNEGEBP dispõe de um currículo, cujo conteúdo do curso foi padronizado para ser desenvolvido por todas as universidades parceiras da Escola de Gestores. Não podemos perder de vista a diversidade e a pluralidade de cada ente federativo, assim como, o caráter identitário.

Questiona-se também quem são os profissionais que estão executando esse programa, uma vez que o quadro docente não é composto por profissionais efetivos da instituição, e não há seleção para fazer parte da Escola de Gestores, revelando fragilidades na qualificação do formador podendo refletir na formação dos cursistas.

A implementação de uma política educacional não é vista como uma parte integral da formulação da política, mas como algo a ser feito depois, por acréscimo. Assim, ela não

\footnotetext{
${ }^{1}$ Neste artigo será adotado o conceito de política pública trabalhado por HÖFLING (2001) entendida como o "Estado em ação" (Gobert, Muller, 1987), ou seja, é o Estado implantando um projeto de governo, através de programas, de ações voltadas para setores específicos da sociedade.
} 
seria valorizada por ser considerada uma simples sucessão de decisões e interações (PEREZ, 2010). É importante examinar a implementação de uma política pública, assim como, seus resultados e se de fato funcionam, no sentido de perceber os processos operados para as políticas alcançar, ou não, os efeitos desejados. E este trabalho vem contribuir neste particular, ao buscar analisar a implementação de uma política pública, direcionada a formação de professores- gestores, no sentido de suscitar uma avaliação desta ação governamental.

Em vista desse cenário, vemos reforçada a necessidade de acompanhar atentamente os resultados de uma política, que emergem de um contexto marcado por inúmeras transformações sociais. Dessa forma, esta pesquisa é relevante para avaliar a continuidade de ações como as do Programa Escola de Gestores no intuito de favorecer a formação continuada dos profissionais de educação - professores gestores - para melhorar a qualificação e o efetivo desempenho de suas funções.

A relevância social do estudo reside, ainda, na possibilidade de oferecer análises sobre as condições de formação e atuação do gestor, de confrontar a própria voz com a regulação instituída pelo PNEGEBP e com isso, vislumbrar a prática discursiva. Segundo Fairclough (2001, p.126) como "modo de luta hegemônica, que reproduz, reestrutura ou desafia as ordens de discurso existentes".

Na metodologia tomou-se a abordagem qualitativa para o tratamento metodológico da problemática a ser investigado. Como se trata de "práticas discursivas" essa abordagem nos direciona para uma aproximação da realidade social no campo da gestão escolar.

Neste trabalho contemplamos as ideias do método de Análise Crítica do Discurso (ACD) de Fairclough (2001), que ao mesmo tempo é teoria e um método de análise. No dizer do autor (2001, p.92): "a prática discursiva é constitutiva tanto de maneira convencional como criativa: contribui para reproduzir a sociedade (identidades sociais, relações sociais, sistemas de conhecimento e crença) como é, mas também contribui para transformá-la".

Com relação à estratégia de pesquisa constitui-se como um estudo de caso sobre a formação de gestores escolares, pois buscaremos entender uma realidade específica do Curso de Especialização em Gestão Educacional oferecido pela Universidade Federal da Paraíba. Para buscarmos respostas as questões deste estudo, utilizaremos um processo dinâmico envolvendo como instrumentos de coleta de dados, levantamento bibliográfico, análise documental, aplicação de questionários e realização de entrevistas semiestruturadas.

Na sistematização dos dados, foi mantida a concepção de Fairclough (2001) acerca 
da análise do discurso que deve ser idealmente um "empreendimento interdisciplinar". Essa concepção no dizer desse autor "envolve um interesse nas propriedades dos textos, na prática social em várias instituições, no relacionamento da prática social com as relações de poder e nos projetos hegemônicos no nível social" (2001, p.276). Nesta fase, recorremos às abordagens teóricas para colocarmos a prática discursiva dos quatro gestores entrevistados aliada ao diálogo acadêmico. Neste interim se faz presente as falas dos sujeitos e as contradições geradas por elas.

\section{A POLÍTICA EDUCACIONAL DO PNEGEBP}

O Plano de Desenvolvimento da Educação aborda como parâmetro de qualidade para a educação, direcionada as escolas públicas de Educação Básica, a social referenciada, mas "tomar a qualidade a partir da dimensão social implica em avaliar as múltiplas determinações que afetam as condições de ensino e de aprendizagem nas escolas e não apenas validar dados numéricos, os quais, muitas vezes, se encontram focados na ótica produtiva" (NARDI; SCHNEIDER, 2012, p.3).

A qualidade social da educação deve envolver uma série de elementos que a justifiquem, como a dimensão intraescolar e a extraescolar. A primeira envolve as condições de oferta do ensino (plano do sistema); a gestão e organização do trabalho escolar (plano da escola); a formação, profissionalização e ação pedagógica do professor (plano do professor) e; as condições de acesso, permanência e desempenho escolar (plano do aluno). Ao passo que a dimensão extraescolar corresponde aos fatores econômicos, socioculturais e às obrigações do Estado no provimento público da educação e na viabilização de condições de formação e valorização da carreira docente (NARDI; SCHNEIDER, 2012).

Situar a educação como política social do Estado significa admitir que os sistemas educacionais respondem de modo específico às necessidades de valorização do capital (NEVES, 2002).

As políticas públicas devem ser de responsabilidade do Estado que não podem ser reduzidas a políticas de governo (HÖFLING, 2001). Para tanto, foi preciso consultar os documentos oficiais do programa da Escola de Gestores a fim de desvelar enunciações presentes na legitimação dessa ação do MEC.

Após a consulta aos documentos do PNEGEBP, percebeu-se que as Diretrizes Nacionais do Curso de Especialização em Gestão Escolar defende a concepção de educação como processo constitutivo e permanente, implicando o reconhecimento da especificidade 
do trabalho docente, da realidade da escola, ou seja, das condições materiais e institucionais no ambiente em que atua o gestor escolar. Como se pode depreender, o documento traz implicações inerentes à diversidade, no entanto, a organização do currículo, a seleção dos textos, a metodologia e a avaliação são predeterminadas pelo MEC.

Esse tema produziu a questão central da investigação desta pesquisa: $A$ política de formação continuada específica para gestores implementada na Paraíba tem alcançado os resultados pretendidos?

Para dar conta desta questão de pesquisa, outras anteriores para nortear a fundamentação teórica eram necessárias: quais são as principais ideias e concepções construídas, no final do século XX e início deste, que compõe a gestão escolar democrática? Qual o perfil do gestor escolar na Paraíba? Qual o perfil definido pela Escola de Gestores? E de outro lado: quais as conotações e implicações geradas a partir da formação de gestores? Quais foram os principais alcances e dificuldades na implementação do Curso de Especialização em Gestão Escolar? Como se dá a relação entre um currículo engessado e a diversidade no cotidiano das escolas? Houve melhorias dos IDEBs nos municípios e nas escolas em que os gestores participaram do curso?

\section{REDEFINIÇÕES NO CONTEXTO DAS POLÍTICAS EDUCACIONAIS}

No delineamento das exigências da formação profissional no âmbito da política educacional brasileira, faz-se necessário retomar a configuração do neoliberalismo enquanto contexto em que ocorreu esse paradigma, estabelecendo os reflexos de sua ideologia política na educação.

A década de 1990, no Brasil, denominada de "Década da Educação", representou o aprofundamento das políticas neoliberais orientadas por meio, entre outros processos, da Reforma do Estado, que engendrou alterações substantivas nos padrões de intervenção estatal, redirecionando mecanismos e formas de gestão, com destaque para as políticas públicas no campo educacional (PERONI, 2003).

Nesse contexto, as ideias neoliberais de privatização foram largamente difundidas pelos meios de comunicação, enfatizando a ineficiência e a insuficiência dos setores públicos, se comparados ao sucesso da iniciativa privada e, aos poucos, restringindo a ação do Estado, garantindo os interesses dos setores privados na economia, o que favoreceu a proliferação dos empresários educacionais (GENTILI, 1998). 
O neoliberalismo em educação deve ser compreendido "muito mais como uma política de regulação do Estado do que como uma política educacional de governo" (HYPÓLITO, 2010, p.04). No setor educacional insere-se na tensão ou dualidade de atuação do Estado: por um lado, a minimização quanto a iniciativas e decisões no nível macro, por outro, a maximização na definição do conhecimento oficial, das normas e dos valores (APPLE, 1999).

As reformas nos sistemas educacionais motivaram debates constantes, e provocou mudanças no terreno econômico, social e político, influenciadas por processos como a globalização e sua repercussão nas transformações sociais, reconfigurando a realidade em todas as partes do mundo. Tais transformações representam o aprofundamento das políticas neoliberais em resposta aos problemas colocados pela crise do desenvolvimento do capitalismo (PERONI, 2003).

Uma concepção de qualidade da educação vinculada às necessidades do mundo moderno passou a ser a bandeira defendida pelos diferentes setores governamentais e empresariais, adquirindo importância estratégica. Surgindo o discurso hegemônico de qualidade total em educação, que tinha como estratégia a transposição de valores mercantis para a educação (SILVA, 2009). Essa ideologia remete à concepção econômica e meramente técnica, gerencial e administrativa, que tem como objetivo o controle do indivíduo. A partir dessa perspectiva, a escola é vista como uma instituição produtiva à imagem e semelhança das empresas (GENTILI, 1994).

Passamos a vivenciar uma educação voltada para os interesses e a lógica do mercado. As formas encontradas para conjugar ampliação do acesso à educação com a redução de custos no setor educacional foram os diferentes mecanismos de privatização da educação. Diante desse quadro, exige-se da escola o cumprimento de finalidades educacionais compatíveis com o interesse capitalista. A trajetória do capital é imprevisível, sempre se baseou na especulação de novos produtos, novas tecnologias, novos espaços e localizações, novos processos de trabalho (HARVEY, 2000).

Nesse contexto, as reformas educacionais implementadas no Brasil foram legitimadas por um discurso que atribuiu a crise da educação à ineficiência de aspectos específicos como gestão, má formação dos professores, currículos inadequados, falta de insumos, entre outros. Assim, foi apontada a ineficiência do Estado na administração educacional e defendida a necessidade da reforma associada à ideia de modernização dos sistemas (PERONI, 2003). 
Dessa forma, a redefinição do papel do Estado gera uma alteração na configuração da própria educação nacional. O movimento de reforma acabou por transferir a educação da esfera da política para a esfera do mercado, negando sua condição de direito social e transformando-a em uma possibilidade de consumo individual, variável segundo o mérito e a capacidade dos consumidores (GENTILI, 1998).

O Estado ao aderir mudanças na sua estrutura criou problemas de ordem estrutural que se consolidaram em reformas educacionais e os resultados não garantiram um ensino com qualidade social, pois ao adotar as estratégias neoliberais reduziu o papel de suas ações e a educação passou a ser objeto do mundo capitalista, estimulada pelo individualismo competitivo (GENTILI, 1998).

\section{O PROGRAMA}

Faz jus destacar que o PNEGEBP é uma ação integrante das políticas de formação da Secretaria de Educação Básica do MEC, iniciada no Governo do Presidente Luiz Inácio Lula da Silva em 2005, na gestão do Ministro da Educação Tarso Genro e reorganizada em 2006, pelo seu sucessor Fernando Haddad, e é voltado a promover a formação continuada dos diretores das escolas públicas de Educação Básica, na modalidade a distância.

É almejado pelo MEC como resultado desta ação, a melhoria dos índices educacionais das escolas e dos municípios atendidos. A referida capacitação diz respeito à mobilização em torno da melhoria da educação básica no Brasil, contribuindo para a melhoria do Índice de Desenvolvimento da Educação Básica (IDEB) das escolas e dos sistemas de ensino (BRASIL/MEC/2009). "Atualmente, é o indicador de maior impacto na qualidade da educação básica por traduzir, simbolicamente, o quanto as unidades escolares, o município e o estado avançaram em suas metas educacionais" (NARDI, SCHENEIDER, 2012, p.3).

O dever do Estado de oferecer escola para todos não o exime de se comprometer com qualquer padrão mínimo de qualidade dos serviços oferecidos. Por esses padrões mínimos não serem delimitados, a estratégia da política de governo é criar um indicador de qualidade, e o que está presente no meio escolar exercido na avaliação como forma de controle é o IDEB. Considerá-lo como um indicador de qualidade, como tem sido apresentado, além de um equívoco, é um risco (OLIVEIRA, 2010).

Desta forma, ao privilegiar a formação e produção de conhecimento pretende que os gestores atuem na perspectiva da gestão democrática e da educação inclusiva. Ao exercerem a profissão com este fim, devem ter como orientação a afirmação do direito à 
educação escolar básica com qualidade social. Assim, os componentes curriculares e a abordagem teórico- metodológica deverão considerar os fatores externos e internos associados à produção e gestão da escola (BRASIL/MEC/ 2007). Sendo assim, esta capacitação deve estar articulada com o enfrentamento dos desafios do cotidiano e singularidades de ações educativas. Espera- se que os profissionais possam atuar de forma reflexiva valendo-se de vários "saberes" (TARDIF, 2002).

O Projeto do Curso de Especialização em Gestão Escolar (PNEGEBP) apresenta um currículo baseado na relação teoria e prática dentro dos marcos da democracia e da cidadania, buscando favorecer melhorias e incentivar inovações na prática cotidiana da gestão escolar, que concorram para a elevação qualitativa do padrão de escolaridade da Educação Básica (BRASIL/ MEC, 2007). A formação dispõe de um currículo, cujo conteúdo do curso foi padronizado para ser desenvolvido por todas as universidades parceiras da Escola de Gestores.

É proposta, no programa, uma formação profissional baseada na dialética entre a teoria e a prática, valorizando também a prática profissional como momento de ampliação do conhecimento, por meio da reflexão, análise e problematização dessa, presente nas soluções que os profissionais encontram em sua atuação. Portanto, nesse curso é propiciado o desenvolvimento da capacidade de refletir, oferecendo perspectivas de análise, para que os gestores escolares compreendam os contextos históricos, sociais, culturais, organizacionais e de si próprios como profissionais (BRASIL/MEC, 2009).

A gestão democrática, o direito à educação e a qualidade social da educação são consideradas, do ponto de vista do Programa Nacional Escola de Gestores da Educação Básica, como os princípios referenciais da política de gestão escolar.

Os objetivos do Curso de Especialização em Gestão Escolar, oferecido pelo PNEGEBP, apontam para uma formação que coloca a gestão democrática no centro das preocupações dos gestores que atuam na escola e nos sistemas de ensino. Esse princípio é determinante para a compreensão da perspectiva de formação com a qual o curso trabalha, e torna-se claro na proposta da formação que a ampliação da democracia no ambiente escolar é um objetivo a ser perseguido, mesmo que com procedimentos organizacionais distintos (BRASIL/MEC/2009).

Participam desta política voltada para a articulação, desenvolvimento e fortalecimento dos sistemas de ensino e das escolas várias instituições, destacando-se a interlocução com entidades e organizações como a Associação Nacional de Dirigentes das Instituições Federais de Ensino Superior (ANDIFES), Associação Nacional de Pós-Graduação e 
Pesquisa em Educação (ANPED), Associação Nacional de Política e Administração da Educação (ANPAE), Fórum de Diretores das Faculdades/ Centros de Educação das Universidades Públicas do País (FORUMDIR), União Nacional de Dirigentes Municipais da Educação (UNDIME) e Conselho Nacional de Secretários Estaduais de Educação (CONSED) (BRASIL/MEC, 2009).

O PNEGEBP atua por meio de parcerias com Instituições de Ensino Superior, com a utilização da Plataforma Moodle no Ambiente Virtual de Aprendizagem. A escolha do MEC por esta modalidade de ensino "deve-se ao fato de que o sistema presencial de educação formal apresenta-se insuficiente para atender as novas demandas sociais de formação, bem como de democratização do saber" (BRASIL/MEC, 2009, p.14).

O referido programa configura-se como marco importante na formação continuada de gestores, na medida em que oferta formação de qualidade, gratuita e a distância com momentos presenciais, beneficiando os gestores de localidades de difícil acesso (CAVALCANTE, 2012).

\section{REPRESENTAÇÕES DO PNEGEBP NA PARAÍBA}

O PNEGEBP firmou adesão com a Universidade Federal da Paraíba (UFPB) em 2007. De acordo com o regulamento da UFPB, o curso de Especialização em Gestão Escolar, realizado em nível de Pós-Graduação Lato Sensu, está estruturado segundo a Resolução N 1, de 8 de junho de 2007 do Conselho Nacional de Educação (CNE) e a Resolução 56/96 do Conselho Superior de Ensino, Pesquisa e Extensão (CONSEPE/UFPB).Trata-se de uma modalidade regular e utilizará a metodologia de educação a distância. A Coordenação Geral do Curso é sediada no Centro de Educação da UFPB, Campus I, em João Pessoa - PB.

Através dessa adesão, para a primeira turma foi possível promover 404 vagas distribuídas em quatro Polos: Polo I - João Pessoa, Polo II - Campina Grande, Polo III - Patos, Polo IV - Cajazeiras.

Quanto aos critérios de seleção dos cursistas, eles são de responsabilidade da instituição executora do programa. Há, no entanto, no texto do projeto de curso, a recomendação para a realização de uma pré-inscrição a ser realizada em conjunto com os sistemas de ensino, e uma posterior seleção técnica a ser feita pelas universidades.

A turma piloto foi iniciada em março de 2009 e teve seu término em junho de 2010. Após a finalização do Curso, a Coordenação da Escola de Gestores na Paraíba apresentou um Relatório para prestar informações acerca do rendimento do curso para a 
Comissão Nacional de Acompanhamento e Avaliação do Curso de Especialização em Gestão Escolar destinado a Diretoria de Fortalecimento Institucional e Gestão Educacional (DFIGE/SEB/MEC).

No Relatório, específico à primeira turma, foi registrado que os objetivos definidos no Programa Nacional da Escola de Gestores referente ao Curso de Especialização em Gestão Escolar foram atingidos: 181 cursistas concluíram suas monografias, 20 concluíram as disciplinas e não apresentaram suas monografias, portanto, receberam certificados de aperfeiçoamento, e aos demais 149 cursistas receberam certidões das disciplinas concluídas. Percebe-se com esses dados que o número de gestores que concluíram a formação é muito baixo.

\section{Vozes dos sujeitos}

Há uma crescente aceitação de que a gestão da escola deve ocorrer de forma descentralizada, com a participação efetiva dos conselhos escolares, sugerindo, propondo, fiscalizando a aplicação de recursos financeiros, construindo junto com a direção o projeto político pedagógico da escola, discutindo a avaliação escolar e a estrutura curricular, buscando estreitar os vínculos sociais com a comunidade local, trazendo os pais de alunos para a discussão não apenas do rendimento de seus filhos, mas, sobretudo, para participarem como cidadãos nas deliberações sobre os rumos da escola.

Com relação às atribuições do gestor escolar, as entrevistadas, num total de cinco, recebeu pouca predominância a dimensão administrativa nas atividades meio do cotidiano escolar. Esse dado constata que o trabalho nas unidades escolares está perpassando por mudanças, no sentido de compartilhar as funções e envolver-se em atividades pedagógicas.

Ainda face às atribuições do gestor, foi constatado que os mesmos consideram a ação administrativa e pedagógica exercida na execução do Projeto Político Pedagógico. Por meio desta afirmação, pode-se considerar que a percepção dos gestores em relação à gestão democrática diz respeito ao trabalho coletivo na consecução da efetivação da qualidade da educação.

O desenvolvimento de uma administração participativa, cujas responsabilidades são distribuídas, é condição para fortalecer vínculos dos membros com a instituição e com o trabalho proposto. Para haver uma participação efetiva é necessário o conhecimento e compartilhamento de informações. 
Pontua-se que através da participação ocorre a ruptura do modelo tradicional de administração escolar e do modelo tradicional de participação, o que frequentemente é confundido por meio de festas escolares, presença em reuniões de cunho pedagógico, e atividades eventuais (LUCK, 2011c). Os fins da educação devem estar associados às necessidades da comunidade escolar, ou seja, o foco das metas deve promover a articulação entre a escola e o público alvo a que destina o trabalho educativo.

$\mathrm{Na}$ observação das atividades que consomem mais tempo, os gestores indicaram que às questões disciplinares em relação aos estudantes tomam a maior parte de seu tempo. Nota-se que as soluções para resolver os problemas causados pela indisciplina ficam a cargo do gestor. Essas atribuições que poderiam ser resolvidas até mesmo pelo professor impedem que o diretor (a) executem outras atividades inerentes à gestão, pois essa atribuição pode implicar em acúmulo de trabalhos administrativos.

Os gestores associam a qualidade social da educação ao trabalho educativo realizado em sintonia com a família, e destacam que está relacionada ao interesse do aluno na sua aprendizagem. No entanto, é preciso refletir que a qualidade de ensino pressupõe o investimento em educação, uma vez que esses recursos ainda não suprem os padrões mínimos estabelecidos.

Predominou em todas as respostas em relação à atuação do gestor a busca pela integração família escola. E destacou-se administrar os recursos materiais e financeiros da escola; construir estratégias para resolver problemas que envolvam estudantes, funcionários e família; e organizar o funcionamento das atividades da escola.

Percebe-se, também, que as gestoras compartilham a construção de um discurso hegemônico de gestão democrática na escola, pautada em princípios do trabalho coletivo, da humanização dos processos educativos, da qualidade de ensino e da valorização da comunidade escolar.

A investigação sobre as dificuldades que marcam a atuação como gestor (a) escolar associa-se às questões de indisciplina, a falta de compromisso, questões pedagógicas e financeiras. Essas questões comprometem o trabalho na gestão conforme explicitado em suas respostas.

O trabalho numa organização educativa depende de muitas variáveis, entre elas o envolvimento da equipe escolar em busca da autonomia para o desenvolvimento do ensino. Alguns gestores escolares afirmaram que não conseguem envolver os professores e estudantes nas atividades que julgam pertinentes para a melhoria da qualidade de ensino. 
Os sujeitos da pesquisa apontaram algumas dificuldades e os momentos de êxito para desenvolver as suas ideias para melhorar a qualidade de ensino envolvendo os profissionais da escola. Em todas as enunciações, é perceptível a contribuição do curso de especialização na promoção da proximidade entre grupo gestor e comunidade escolar. Essa aproximação favoreceu a análise coletiva da realidade escolar, ainda que subjetiva, da realidade escolar na tomada de decisão.

Chama-nos a atenção o discurso de uma das gestoras ao afirmar que "Copia exemplos de boas gestões em revistas, sites, entrevistas, adaptando-as a nossa realidade", evidencia-se que a gestora busca atualizar-se em relação ao desempenho de outros gestores, e por meio de outras experiências tenta trazer para a unidade escolar em que atua melhorias na prática.

Vale ressaltar, mediante aos depoimentos que existe um trabalho, ainda tímido, na perspectiva da democratização da gestão escolar. Os dados apresentados nos questionários apontam para a participação da comunidade escolar, com ênfase nos professores para o desenvolvimento de projetos pedagógicos.

\section{CONCLUSÕES}

A análise realizada nesta pesquisa permite-nos reconhecer nas políticas educacionais para a formação docente, desta segunda década do século XXI, o fortalecimento de práticas democráticas na gestão escolar e, de outro lado, a emergência de melhorias na qualidade da educação.

Parece-nos, assim, que a proposta do Programa Escola de Gestores acerta quando não toma a gestão escolar como um campo com conhecimentos específicos e próprios ou mesmo técnico, e prioriza uma formação mais ampla, sem descuidar de questões mais específicas da escola e do contexto.

A atuação na gestão demanda formação na área, e torna-se tarefa essencial para aprimorar os conhecimentos, visto que a educação pressupõe capacitação. A função do gestor escolar em instituições públicas possui elevada complexidade, exigindo competências apropriadas para o exercício do cargo.

Essa análise foi relevante para avaliar resultados alcançados por uma formação, que nunca foi disponível na Paraíba, e para validarmos a continuidade de ações como as do Programa Escola de Gestores, no intuito de favorecer a formação continuada dos profissionais 
de educação - professores gestores - para que a melhoria da educação aconteça de fato.

Em consonância à análise efetuada, o Programa Nacional Escola de Gestores da Educação Básica Pública, na perspectiva da formação continuada, contribuiu de forma singular para a efetivação de mudanças, ainda que peculiares, na prática das três gestoras entrevistadas, que participaram do programa na rede pública municipal estudada, conforme pode ser constatado em seus discursos.

Essas mudanças ocorreram, principalmente, em relação aos aspectos pedagógicos da escola, em detrimento dos aspectos administrativos, na medida em que os conhecimentos adquiridos no curso são aplicados na escola, fazendo a relação da teoria com a prática, ou seja, as gestoras primam pela participação como o meio de efetivar a gestão democrática na escola, em busca de uma educação de qualidade.

Acreditamos que o objetivo desta pesquisa foi alcançado, no sentido de ter identificado contribuições do Curso de Especialização em Gestão Escolar nas ações das gestoras que participaram dessa formação, ainda que estes se apresentem de forma multifacetada. Não obstante, há elementos que ainda podem ser estudados, como por exemplo, qual a percepção das pessoas que interagem ou que interagiram no ambiente escolar com os cursistas e qual a constatação destes em relação às mudanças na gestão por parte dos cursistas egressos.

No levantamento das contribuições do curso, nos deparamos com o discurso de uma das gestoras que reconheceu e assumiu que não era uma gestora democrática e passou a ser ao longo do processo de formação, o que para esta pesquisa é de grande valor demonstrar uma mudança na postura política perante as ações numa gestão escolar, marcada por autoritarismo e supremacia através do poder hierárquico.

Constatamos também que não é possível aferir a relação da real contribuição do curso na melhoria dos índices da escola nas quais as gestoras atuam, visto que faz pouco tempo o término dessa formação. Bem como, qual a importância dele na melhoria dos índices da escola, uma vez que ocorrem a cada dois anos a aplicação dos testes, análise, avaliação e divulgação do IDEB.

Há outras possibilidades de estudo como analisar a realidade de cursistas egressos de outros municípios e suas percepções sobre as mudanças efetivadas pelo gestor (a) no âmbito escolar, tomando por parâmetro a formação do PNEGEBP. Assim como, se nos próximos anos houve melhorias nos IDEBs das escolas em que os gestores (as) atuam, uma vez que o programa seleciona apenas unidades escolares com índices considerados pífios, 
abaixo da média nacional. E o programa objetiva contribuir para a elevação do IDEB e melhoria da qualidade social, através de uma gestão escolar eficiente.

Foi interessante estudar as contribuições de uma política educacional porque não nos atemos a analisar o processo de formulação, porém nos detemos a avaliar o processo operado para essa política alcançar os efeitos desejados. Pelo fato de ainda os tomadores de decisão acerca de uma política pública tender a assumir que as decisões trazem automaticamente a mudança através de formação (PEREZ, 2010).

A implantação de uma política educacional não é vista como uma parte integral da formulação da política, mas como algo a ser feito depois, por acréscimo. Assim, ela não seria valorizada por ser considerada uma simples sucessão de decisões e interações (PEREZ, 2010). E este trabalho vem contribuir neste particular ao buscar analisar os resultados alcançados através da implementação de uma política pública, direcionada a formação de professores- gestores, que de forma singular abrangeu uma cidade pequena, mas que tem contribuições a dar na avaliação desta ação governamental.

Em vista deste cenário, vemos reforçada a necessidade de acompanhar atentamente os resultados de uma política que intenta contribuir com a qualificação do gestor (a) escolar na perspectiva da gestão democrática e da efetivação do direito à educação escolar básica com qualidade social, que emergem de um contexto marcado por infinitas transformações sociais.

No transcorrer da Especialização, os gestores se depararam com proposições desafiadoras próprias da educação a distância e tiveram que se adaptar as ferramentas informacionais, inclusive do uso da Plataforma Moodle. Esses conhecimentos auxiliarão os profissionais envolvidos a aprimorar o uso de ferramentas informacionais, serviços, metodologia e estratégias dentro desta nova possibilidade de aprendizagem.

A experiência descrita na análise demonstrou que o Curso de Especialização em Gestão Escolar conseguiu levar gestores de escolas públicas a uma reflexão mais substantiva e profunda de sua realidade social. Consideramos válida a continuidade deste curso na Universidade Federal da Paraíba, uma vez que permite abranger cursistas em diversas localidades com os recursos da Educação a Distância, proporcionando o acesso a pessoas que, de outra forma, possivelmente, não poderão fazê-lo. 


\section{REFERÊNCIAS}

AGUIAR, Márcia Angela da S.. A política nacional de formação docente, o Programa Escola de Gestores e o trabalho docente. Educar em Revista, Curitiba, Brasil, n. especial 1, p. 161-172, 2010. Editora UFPR.

APPLE, M. Políticas culturais e educação. Porto Editora, 1999.

BRASIL. Ministério da Educação. PDE: Plano de Desenvolvimento da Educação:Prova Brasil: Ensino Fundamental: Matrizes de referenciais, tópicos e descritores. Brasília: MEC, SEB; Inep, 2008.

BRASIL, Escola de Gestores da Educação Básica: Doc. Diretrizes Nacionais do Programa Escola de Gestores da Educação Básica Pública.Brasília:MEC. Educação, 2009. Disponível em: http://portal.mec.gov.br/index.php?ltemid=\&gid=879\&option... Acesso em maio de 2012.

BRASIL, Escola de Gestores da Educação Básica: Documento. Projeto curso de especialização em gestão escolar (Lato Sensu). Brasília: Ministério da Educação, 2007. Disponível em: http://portal.mec.gov.br/index.php?option=com docman\&task... Acesso em maio de 2012.

BRASIL. Ministério da Educação. Expansão. Disponível em:

$<$ http://reuni.mec.gov.br/index.php?option=com content\&view=article\&id=100\&ltemid=81. Acesso em: 29 de maio de 2012.

CAVALCANTE, Eleny Brandão. Sala ambiente e Projeto Vivencial: um espaço de reflexão sobre a gestão escolar. In: SOUSA COLARES, Maria Lília Imbiriba; XIMENES-ROCHA, Solange Helena; COLARES, Anselmo Alencar (Orgs.) Gestão Educacional: práticas reflexivas e proposições para escolas públicas. Belém: GTR, 2012.

FAIRCLOUGH, Norman. Discurso e mudança social. Izabel Magalhães, coordenadora da tradução, revisão técnica e prefácio. Brasília: Editora UNB (2001) 2008 reimpressão.

FOUCAULT, Michel. Microfísica do poder. Rio de Janeiro, Graal, 1979.

GENTILI, Pablo. A falsificação do consenso: simulacro e imposição na reforma educacional do neoliberalismo. Petrópolis, Rio de Janeiro: Vozes, 1998.

- Políticas Educacionais no Contexto do Neoliberalismo: os significados da privatização no campo educacional. In. OLIVEIRA, Maria Neusa de. As Políticas Educacionais no contexto da Globalização. Ilhéus: Editus, 1999.

HARVEY, David. Condição Pós-moderna. 9. ed. São Paulo: Edições Loyola, 2000.

HYPOLITO, Álvaro Moreira. Políticas curriculares, estado e regulação. Educ. Soc., Campinas, v. 31, n. 113, p. 1337-1354, out.-dez. 2010.

HÖFLING, Eloísa de Mattos. Estado e Políticas (Públicas) Sociais. Caderno Cedes, ano XXI, $n^{\circ} 55$, novembro/2001.

NARDI, Elton Luiz; SCHNEIDER, Marilda Pascal. Qualidade (social) na educação básica: o desafio da construção nos municípios do oeste catarinense. IX ANPED SUL. Seminário de 
pesquisa da Região Sul. 2012.

NASCIMENTO, Lindalva Gouveia. A prática discursiva das contribuições da Escola de Gestores para a gestão escolar democrática. 132f. Dissertação de Mestrado. João Pessoa. Universidade Federal da Paraíba, 2012.

NEVES, Lúcia Maria Wanderley. Educação e Política no Brasil de hoje. 3ạ Ed. São Paulo, Cortez, 2002.

NEVES, Carmem Moreira de Castro. Autonomia da escola pública: um enfoque operacional. In: VEIGA, Ilma Passos Alencastro. Projeto-político-pedagógico: uma construção possível. 28ed. Campinas, SP: Papirus, 2010, pp. 95-129.

OLIVEIRA, Romualdo Portela. A qualidade do ensino como parte do direito à educação: um debate em torno dos indicadores. Trabalho apresentado para prova de concurso para Professor Titular da Faculdade de Educação da Universidade de São Paulo, 2010. Mimeo.

PEREZ, José Roberto Rus. Por que pesquisar implementação de políticas educacionais atualmente? Educ. Soc., Campinas, v. 31, n. 113, p. 1179-1193, out.-dez., 2010.

PERONI, Vera. Política educacional e papel do Estado no Brasil dos anos 1990. São Paulo: Xamã, 2003.

SILVA, M. Abádia da. Qualidade Social da Educação pública: algumas aproximações. Cad. Cedes, Campinas, vol.29, n.78, p.216-226, maio/ago.2009.

TARDIF, Maurice. Saberes docentes e formação profissional. 2.ed. Petropólis; Vozes, 2002.

TEIXEIRA, Marilza Aparecida Pereira. Formação para diretor escolar da educação básica: o Programa Nacional Escola de Gestores no estado do Paraná. Dissertação (Mestrado em Educação) - Setor de Educação, Universidade Federal do Paraná. 135fls. - Curitiba, 2011.

UFPB. Resolução N. 59/2007. Artigo 28, incisos XV e XVI do Estatuto da UFPB de 30 de novembro de 2007. 